\title{
PROCESSAMENTO MÍNIMO DE UVAS DE MESA SEM SEMENTE ${ }^{1}$
}

\author{
BEN-HUR MATTIUZ2, ANA CAROLINA ALMEIDA MIGUEL², JAIR COSTA NACHTIGAL ${ }^{3}$, \\ JOSÉ FERNANDO DURIGAN², UMBERTO ALMEIDA CAMARGO ${ }^{4}$
}

\begin{abstract}
RESUMO - O trabalho teve como objetivo avaliar os aspectos qualitativos de uvas de mesa apirênicas (sem sementes) quando submetidas ao processamento mínimo e armazenadas sob refrigeração. Para tanto, foram utilizadas uvas da cultivar BRS Morena e da Seleção Avançada no 8, produzidas na Embrapa Uva e Vinho/Estação Experimental de Viticultura Tropical (da Embrapa de Jales). Os cachos, depois de higienizados, imersos em água clorada a $300 \mathrm{mg}$ de cloro. $\mathrm{L}^{-1}$ por $5 \mathrm{~min}$., foram mantidos em câmara fria, a $12^{\circ} \mathrm{C}$, por $12 \mathrm{~h}$. Pessoas treinadas e com proteção adequada procederam à degrana dos cachos e ao posterior enxágüe das bagas com água clorada $\left(20 \mathrm{mg} \cdot \mathrm{L}^{-1}\right)$ a $12^{\circ} \mathrm{C}$. Depois de escorrido o excesso de água, as bagas foram acondicionadas em bandejas de tereftalato de polietileno (PET) transparente com tampa e com capacidade para $500 \mathrm{~mL}$. Cada unidade, contendo $200 \mathrm{~g}$ de bagas, foi armazenada a $2,5 \pm 1^{\circ} \mathrm{C}$ e $88 \%$ UR por até 36 dias. Avaliaram-se a perda de massa fresca, a evolução da aparência, a coloração e os teores de sólidos solúveis totais (SST), e de acidez titulável (AT). Nas condições do experimento, os produtos minimamente processados da cv. BRS Morena e da Seleção 8 apresentaram baixa perda acumulada de massa fresca $(0,16 \%)$. O produto da cv. Morena apresentou-se mais escuro $(L=25,04)$ e mais arroxeado $\left(h^{\circ}=332,88\right)$ que o da Seleção $8\left(L=29,86\right.$ e $\left.h^{\circ}=345,11\right)$, propiciando-lhe melhor qualidade visual. O suco da 'BRS Morena' apresentou maiores teores de SST $\left(22,17^{\circ}\right.$ Brix $)$ e menores para a AT $(0,56 \%)$, o que resultou em uma relação SST/AT maior e melhor $(39,76)$ que o da Seleção 8 (18,81). Acv. BRS Morena também apresentou boa manutenção da aparência e, portanto, da qualidade comercial, por 33 dias a $2,5^{\circ} \mathrm{C}$, superior ao obtido para a Seleção 8 (24 dias).
\end{abstract}

Termos para indexação: Vitis sp, armazenamento refrigerado, uvas apirênicas, pós-colheita, minimamente processado.

\section{SEEDLESS TABLE GRAPES MINIMALLY PROCESSED}

ABSTRACT - This work evaluated the qualitative aspects of apirenic table grapes (seedless), cv. BRS Morena and Selection 8, when minimally

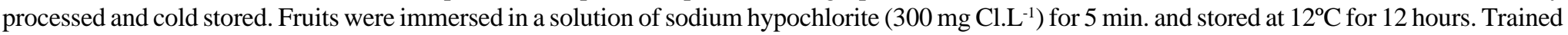
personnel using adequate protection and disinfected equipment, removed the berries and rinsed them with chlorinated water $\left(20 \mathrm{mg} . \mathrm{L}^{-1}\right)$. Berries were packaged in transparent polyethylene terephthalate containers and stored at $2.5 \pm 1^{\circ} \mathrm{C}$, and $88 \% \mathrm{RH}$ for 36 days. The loss of fresh mass, development of appearance and color, and contents of total soluble solids (TSS) and titratable acidy (TA) were done. Products of 'BRS Morena' and Selection 8 showed low percentage of accumulated loss of fresh mass $(0.16 \%)$. The berries of cultivar BRS Morena were darker $(L=25.04)$ and purpler colored $\left(h^{\circ}\right.$ $=332.88)$ than the Selection $8\left(L=29.86\right.$ and $\left.h^{\circ}=345.11\right)$, bringing a product with better visual quality. Juice of 'BRS Morena ' had high content of TSS $\left(22.17^{\circ}\right.$ Brix $)$ and low of TA $(0.56 \%)$, that resulted in a ratio (39.76) better and bigger than the Selection 8 (18.81). Products from cv. BRS Morena presented good appearance and commercial quality for 33 days at $2.5^{\circ} \mathrm{C}$ that was better than Selection 8 (24 days).

Index terms: Vitis sp, cold storage, apirenic table grapes, postharvest, fres-cut.

\section{INTRODUÇÃO}

A produção mundial de uvas de mesa foi de 10,4 milhões de toneladas em 2002, sendo que a China e a Turquia figuram como os maiores produtores (AGRIANUAL, 2004).

Atualmente, as variedades de uvas apirênicas (sem sementes) têm despertado interesse dos produtores, dada a grande aceitação pelos mercados nacional e internacional, além da agregação de valor ao produto. Entretanto, as principais cultivares sem sementes, como Superior Seedless, Thompson Seedless e Crimson Seedless, apresentam produções muito baixas ou inconstantes nos principais pólos produtores brasileiros (Nachtigal, 2003).

Em 2003, a Embrapa Uva e Vinho lançou as primeiras cultivares de uva de mesa sem semente - BRS Clara, BRS Linda e BRS Morena - com alta fertilidade natural nas condições tropicais do Brasil e com frutas de boa qualidade (Camargo et al., 2003).

Os principais problemas pós-colheita das uvas de mesa são as podridões, a desidratação do engaço e a degrana, causando perdas e prejudicando a qualidade dos produtos.

Nos últimos anos, tem ocorrido mudança significativa nos hábitos alimentares da população brasileira (Souza, 2001). A busca da longevidade e da qualidade de vida faz com que as pessoas procurem alimentos mais saudáveis, aumentando o consumo de frutas e hortaliças frescas em detrimento dos produtos industrializados.

O processamento mínimo tem por objetivo suprir essas exigências, disponibilizando produtos frescos que são comercializados limpos, convenientes, e que podem ser preparados e consumidos em menor tempo
(Cantwell, 1995). Além disso, torna possível a agregação de valor aos produtos, maior aproveitamento da produção, redução das perdas póscolheita e maior eficiência no manejo de resíduos. Em uvas, o processamento mínimo poderia ser uma alternativa interessante, pois permitiria valorizar as bagas com boa qualidade, provenientes de cachos que não se prestariam à comercialização devido a problemas de degrana ou de bagas defeituosas.

Entretanto, as frutas minimamente processadas ainda são um desafio, devido à falta de conhecimento a respeito do comportamento fisiológico, químico e bioquímico de seus produtos. As operações envolvidas na preparação de frutas minimamente processadas, geralmente, são responsáveis pela curta vida útil das mesmas, a qual fica restrita, em alguns casos, a somente 3-4 dias (O'Connor-Shaw et al., 1994).

O objetivo deste trabalho foi avaliar os aspectos qualitativos de uvas de mesa sem sementes, quando submetidas ao processamento mínimo e armazenadas sob refrigeração.

\section{MATERIAL EMÉTODOS}

Foram utilizadas uvas de mesa apirênicas (sem sementes) da cultivar BRS Morena e da Seleção 8, procedentes da Estação Experimental de Viticultura Tropical, Jales-SP, pertencentes à Embrapa Uva e Vinho. A cv. BRS Morena foi obtida do cruzamento 'Marroo Seedless' x 'Centennial Seedless', realizado em 1998, e apresenta produtividade de 20 a 25 t.ha $^{-1}$, bagas de coloração preta, textura crocante e elevado grau glucométrico (Camargo et al., 2003). A Seleção 8 é uma seleção apirênica com potencial para ser lançada como cultivar e que apresenta bagas de tamanho grande e de coloração avermelhada.

\footnotetext{
${ }^{1}$ (Trabalho 047/2004). Recebido: 25/03/2004. Aceito para publicação: 02/08/2004.

${ }^{2}$ UNESP-FCAV, Departamento de Tecnologia. Via de acesso Prof. Paulo Donato Castellane, s/n. CEP: 14.884-900. Jaboticabal-SP. benhur@ fcav.unesp.br.

${ }^{3}$ Embrapa Uva e Vinho - Estação Experimental de Viticultura Tropical, CP. 241, CEP: 15700-000, Jales-SP.

${ }^{4}$ Embrapa Uva e Vinho, CP130, CEP: 95700-000, Bento Gonçalves-RS.
} 
As uvas foram colhidas 120 dias após a poda e acondicionadas em caixas de papelão com tampa. Os cachos foram transportados, de forma rápida e cuidadosa, ao Laboratório de Tecnologia dos Produtos Agrícolas da UNESP/FCAV - Câmpus de Jaboticabal-SP.

No laboratório, os cachos foram higienizados por imersão em água clorada a $300 \mathrm{mg}$ de cloro. $\mathrm{L}^{-1}$, por 5 min e mantidos em câmara fria, a $12^{\circ} \mathrm{C}$, por $12 \mathrm{~h}$. Pessoas treinadas e com proteção adequada procederam à degrana dos cachos e ao enxágüe das bagas com água clorada (20 mg de cloro. $\left.\mathrm{L}^{-1}\right)$. Em seguida, estas foram colocadas em peneiras plásticas para escorrer o excesso de água e, logo após, acondicionadas em bandejas de tereftalato de polietileno (PET) transparente com tampa e com capacidade para $500 \mathrm{~mL}$ (Neoform ${ }^{\circledR} \mathrm{N}-90$ ). As unidades, contendo $200 \mathrm{~g}$ do produto, foram armazenadas sob refrigeração $\left(2,5 \pm 1^{\circ} \mathrm{C}, 88 \pm 6 \% \mathrm{UR}\right)$.

A cada três dias, foi avaliada a massa fresca, mediante a pesagem em balança analítica, o que permitiu expressar as variações médias em porcentagem. Neste mesmo lote, também, foi realizada, a cada três dias, a determinação da aparência através da atribuição de notas, onde: 4 (ótima) = baga túrgida, sem fungos, cor normal; 3 (boa) = baga sem brilho, sem fungos, cor normal; 2 (aceitável) = baga sem brilho e sem fungos, porém de cor escurecida; 1 (ruim) = baga murcha, com fungos e escurecida. Atribuiu-se a nota 2 como sendo condição para descarte comercial. Semanalmente, foram realizadas análises de coloração, utilizando-se de reflectômetro Minolta Chomameter CR 200b, que utiliza o sistema da CIE 1976 (Minolta Corp., 1994), permitindo determinar a luminosidade $(L)$, o ângulo de cor $\left(h^{o}\right)$ e a cromaticidade $(C)$ das bagas. Nesse período, também foram determinados os teores de sólidos solúveis totais (SST) e de acidez titulável (AT), conforme método nº 932-12 e 942,15 da AOAC (1997), respectivamente.

$\mathrm{O}$ experimento foi conduzido em delineamento inteiramente casualizado, num esquema fatorial composto por dois fatores: material (cv. BRS Morena e Seleção 8) e dias de armazenamento ( $0 ; 7 ; 14 ; 21 ; 28$ e 35). Foram utilizadas três bandejas (repetições) para as determinações químicas, das quais se tomavam 30 bagas para a determinação da coloração (luminosidade, ângulo de cor e cromaticidade).

\section{RESULTADOSEDISCUSSÃO}

Verificou-se que, durante o período de armazenamento, a perda de massa foi pequena pelos produtos dos dois materiais testados, havendo diferença significativa entre eles (Figura 1), sendo que a cv. BRS Morena apresentou maior valor acumulado médio $(0,17 \%)$ que a Seleção $8(0,15 \%)$. Os valores obtidos foram inferiores aos citados por Kluge et al. (2002), que consideram perdas de água de $1,2 \%$ como prejudiciais às características organolépticas de uvas. Os baixos valores devem-se, provavelmente, aos efeitos conjugados da temperatura de armazenamento, aliada à embalagem e à modificação da atmosfera no seu interior. Este fato, além de propiciar um retardo na atividade respiratória do material, evitou a formação de um grande déficit de pressão de vapor e, conseqüentemente, a perda de água pelo produto. Esses valores foram menores que os obtidos por Mattiuz (2002), que constatou uma perda acumulada de $3,57 \%$ em goiabas 'Paluma' minimamente processadas e armazenadas a $3^{\circ} \mathrm{C}$. $\mathrm{O}$ fato de as goiabas terem sofrido um processamento mais severo que o da uva, além das diferenças nos processos metabólicos normais dessas frutas, pode ter contribuído para essa diferença (Kader, 2002).

A piora na aparência dos materiais testados evoluiu de maneira similar, conforme o exposto na Figura 2. Acv. BRS Morena apresentou, ao longo do período de armazenamento, melhor manutenção da qualidade comercial, somente atingindo a nota para o descarte comercial (nota 2) após 36 dias de armazenamento. Normalmente, frutas minimamente processadas apresentam curta vida útil, restrita a poucos dias (Brecht, 1995). Teixeira et al. (2001) obtiveram viabilidade comercial de 7 dias para mamões 'Formosa' minimamente processados e armazenado a $3^{\circ} \mathrm{C}$. Durigan \& Sargent (1999) observaram redução gradativa na aparência de melão 'Cantaloupe' minimamente processado, obtendo também um período adequado para a comercialização de até 7 dias. Segundo Cantwell \& Suslow (2002), as operações envolvidas na preparação de frutas e hortaliças minimamente processadas, geralmente, reduzem a vida de prateleira das mesmas, pois levam a mudanças fisiológicas que resultam em prejuízos à aparência. A Seleção 8 conservou aparência geral boa até o $24^{\circ}$ dia, revelando no $27^{\circ}$ descoloração, murchamento e perda de textura. A preservação do frescor é um fator de relevância, visto que $83 \%$ da decisão de adquirir ou rejeitar um produto é determinado pela aparência ou condição em que o produto se encontra (Kader, 2002).

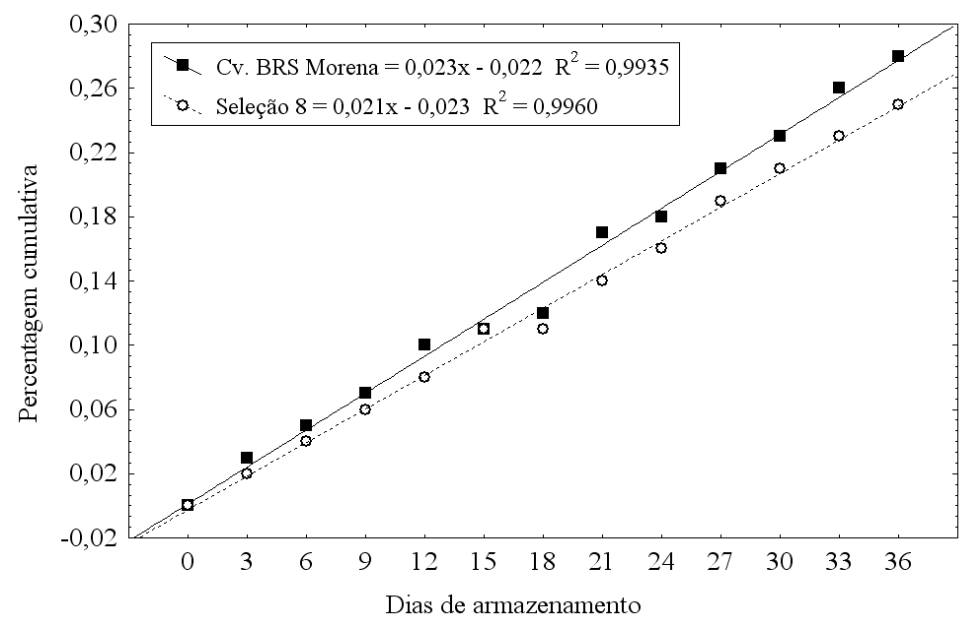

FIGURA 1 - Evolução da perda de massa fresca de uvas de mesa apirênicas minimamente processadas e armazenadas sob refrigeração $\left(2,5 \pm 1^{\circ} \mathrm{C}, 88 \pm 6 \% \mathrm{UR}\right)$.

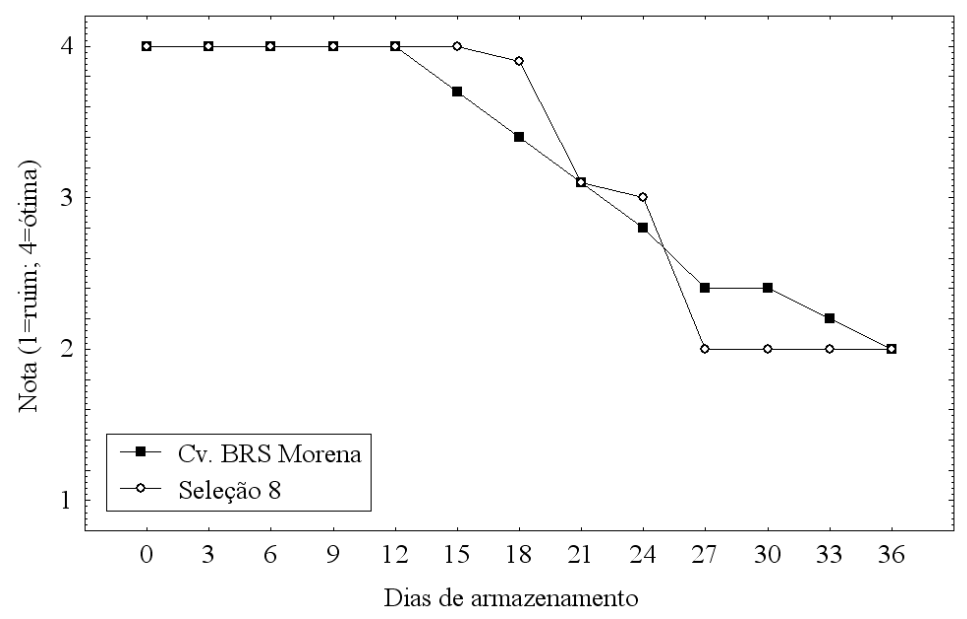

FIGURA 2 - Evolução da aparência externa de uvas de mesa apirênicas minimamente processadas e armazenadas sob refrigeração $\left(2,5 \pm 1{ }^{\circ} \mathrm{C}, 88 \pm 6 \% \mathrm{UR}\right)$.

A análise de variância dos dados de coloração revelou significância nos efeitos principais das variáveis testadas (Tabela 1). Observa-se que a cv. BRS Morena apresentou valores médios menores de luminosidade e de ângulo de cor que os da Seleção 8, revelando coloração mais arroxeada. De acordo com Chitarra \& Chitarra (1990), os produtos de cor forte e brilhante são os mais procurados pelos consumidores, pois estes correlacionam as mudanças de coloração, por ocasião do amadurecimento, com o aumento da doçura e das características organolépticas. Dessa maneira, normalmente, a decisão de compra recai sobre produtos coloridos, no caso das uvas, principalmente a cor vermelha, rosada e preta.

Apesar de ocorrerem diferenças entre os dias de avaliação, o que foi atribuído às amostras individuais das cultivares, os valores de luminosidade e ângulo de cor ao longo do armazenamento indicam que as bagas mantiveram boa qualidade visual durante todo o período. Os parâmetros que definem a coloração podem ser indicativos da perda de qualidade, pois, à medida que um produto muda suas características originais, seja escurecendo, seja adquirindo outra tonalidade, há o comprometimento da sua aparência e, por conseguinte, da sua aceitabilidade pelo mercado consumidor (Chitarra, 1994). No julgamento 
da qualidade dos produtos de origem vegetal, principalmente frutas e hortaliças, a cor é considerada como um dos fatores mais importantes (Kader, 2002).

Os valores para a intensidade da cor $(C)$ aumentaram com o armazenamento e, provavelmente, contribuíram para a manutenção da cor A variação deste parâmetro foi significativamente mais expressiva na 'BRS Morena', que variou de 4,34 para 6,76, quando comparada à Seleção 8, que variou de 5,51 para 7,35. Esses aumentos podem ser resultado da oxidação de fenóis que estimulam a atividade de enzimas de escurecimento, como a peroxidase, resultando em alterações na cor durante o armazenamento (Hernández et al., 1996). Alterações dessa natureza podem gerar compostos de coloração escura, assemelhando-se aos pigmentos naturais da fruta e, deste modo, contribuindo para a manutenção da cor. A intensidade da cor apresentada por tais produtos depende diretamente da quantidade e da qualidade dos pigmentos que neles se encontram. Fatores como variedade, maturação e tipo de processamento têm papel fundamental na cor final apresentada pelo produto após o processamento. Mattiuz (2002) também observou a manutenção da coloração durante os 9 dias em que foram armazenadas goiabas minimamente processadas.

Pode-se verificar na Tabela 2 que a cv. BRS Morena apresentou maiores valores médios para os teores de sólidos solúveis totais (SST) e menores para a acidez titulável (AT), o que resultou em uma relação SST/ AT muito superior à da Seleção 8. Essa relação é um importante atributo qualitativo, uma vez que indica o gosto inerente ao produto, o qual é resultado da contribuição dos componentes responsáveis pela acidez e doçura (Mattiuz, 2002). O equilíbrio entre os teores de açúcares e ácidos obtidos neste trabalho, de acordo com Carvalho \& Chitarra (1984), permite inferir que os materiais testados apresentaram sabor agradável.

TABELA 1 - Evolução da coloração externa de uvas de mesa apirênicas submetidas ao processamento mínimo e armazenadas sob refrigeração $\left(2,5 \pm 1{ }^{\circ} \mathrm{C}, 88 \pm 6 \% \mathrm{UR}\right)$.

\begin{tabular}{lccl}
\hline \multicolumn{1}{c}{ Variá vel } & \multicolumn{1}{c}{$\boldsymbol{L}$} & $\boldsymbol{h}^{\boldsymbol{o}}$ & $\boldsymbol{C}$ \\
\hline Material & & & \\
Cv. BRS Morena & $25,04 \mathrm{~b}$ & $332,88 \mathrm{~b}$ & $5,57 \mathrm{~b}$ \\
Seleção 8 & $29,86 \mathrm{a}$ & $345,11 \mathrm{a}$ & $6,42 \mathrm{a}$ \\
$d m s$ & 0,26 & 2,53 & 0,36 \\
Dias & & & \\
0 & $27,90 \mathrm{ab}$ & $335,49 \mathrm{c}$ & $4,93 \mathrm{c}$ \\
7 & $27,06 \mathrm{dc}$ & $337,70 \mathrm{bc}$ & $5,46 \mathrm{bc}$ \\
14 & $28,44 \mathrm{a}$ & $339,12 \mathrm{abc}$ & $6,09 \mathrm{~b}$ \\
21 & $27,60 \mathrm{bc}$ & $342,75 \mathrm{ab}$ & $6,00 \mathrm{~b}$ \\
28 & $26,71 \mathrm{~d}$ & $337,98 \mathrm{bc}$ & $6,21 \mathrm{ab}$ \\
35 & $26,79 \mathrm{~d}$ & $335,46 \mathrm{c}$ & $6,23 \mathrm{ab}$ \\
dms & 0,66 & 6,38 & 0,92 \\
\hline C.V. (\%) & 4,60 & 3,61 & 3,02
\end{tabular}

$L=$ luminosidade; $h^{o}=$ ângulo de cor; $C=$ cromaticidade. Médias seguidas de, pelo menos, uma letra comum, nas colunas, não diferem significativamente entre si, pelo teste de Tukey $(\mathrm{P}<0,05)$.

TABELA 2 - Teores de sólidos solúveis totais (SST), acidez titulável (AT) e relação SST/AT de uvas de mesa apirênicas submetidas ao processamento mínimo e armazenadas sob refrigeração $\left(2,5 \pm 1^{\circ} \mathrm{C}, 88 \pm 6 \% \mathrm{UR}\right)$.

\begin{tabular}{lccc}
\hline \multicolumn{1}{c}{ Variável } & $\begin{array}{c}\text { SST } \\
\left({ }^{\circ} \text { Brix }\right)\end{array}$ & $\begin{array}{c}\text { AT } \\
(\%)\end{array}$ & SST/AT \\
\hline Material & & & \\
Cv. BRS Morena & $22,17 \mathrm{a}$ & $0,56 \mathrm{~b}$ & $39,76 \mathrm{a}$ \\
Seleção 8 & $16,06 \mathrm{~b}$ & $0,86 \mathrm{a}$ & $18,81 \mathrm{~b}$ \\
$d m s$ & 0,43 & 0,02 & 0,73 \\
Dias & & & \\
0 & $19,43 \mathrm{a}$ & $0,73 \mathrm{ab}$ & $29,03 \mathrm{ab}$ \\
7 & $18,77 \mathrm{a}$ & $0,70 \mathrm{ab}$ & $28,40 \mathrm{~b}$ \\
14 & $19,12 \mathrm{a}$ & $0,74 \mathrm{a}$ & $28,23 \mathrm{~b}$ \\
21 & $18,93 \mathrm{a}$ & $0,68 \mathrm{~b}$ & $29,95 \mathrm{ab}$ \\
28 & $18,97 \mathrm{a}$ & $0,71 \mathrm{ab}$ & $29,15 \mathrm{ab}$ \\
35 & $19,27 \mathrm{a}$ & $0,68 \mathrm{~b}$ & $30,37 \mathrm{a}$ \\
$d m s$ & 1,11 & 0,06 & 1,88 \\
\hline C.V. $(\%)$ & 3,26 & 4,38 & 3,61 \\
Med & & &
\end{tabular}

Médias seguidas de, pelo menos, uma letra comum, nas colunas, não diferem significativamente entre si, pelo teste de Tukey $(\mathrm{P}<0,05)$.
O conteúdo de SST manteve-se estável até o $35^{\circ}$ dia, enquanto as variações na acidez e na relação SST/AT também não caracterizaram tendência significativa. Chitarra \& Chitarra (1990) citam que o decréscimo dos teores de açúcares, em virtude do aumento do metabolismo, pode ser considerado um fator que atua negativamente na qualidade. A manutenção das características químicas, por 9 dias, também foi observada por Mattiuz et al. (2003) em goiabas minimamente processadas. Contrariamente, O'Connor-Shaw et al. (1994) constataram perdas na qualidade e na doçura, com incremento no gosto amargo de melões, kiwis, papaias e abacaxis minimamente processados.

Pela análise da acidez titulável, verifica-se que a 'BRS Morena' se apresentou menos ácida, com $0,56 \%$ de ácido tartárico, em relação à Seleção 8 (0,86\%). Esses valores estão aquém dos citados por Carvalho \& Chitarra (1984), que consideraram valores superiores a $1,5 \%$ prejudiciais à qualidade de uva para comercialização. A acidez em produtos minimamente processados é benéfica sob o ponto de vista microbiológico, pois inibe o crescimento de patógenos nocivos à saúde humana, de tal forma que não comprometa a qualidade sensorial deste mesmo produto.

No decurso do armazenamento, ocorreu crescimento fúngico no material da cv. BRS Morena, reduzindo a vida útil do produto para 33 dias. Entretanto, cabe salientar que, nas embalagens onde não ocorreu contaminação, o produto conseguiu atingir até 67 dias de armazenamento com boa qualidade. Essa projeção, aliada às demais características analisadas, como a melhor coloração, a melhor aparência, a alta relação SST/AT e a manutenção destas qualidades ao longo do período avaliado sinalizam o grande potencial desta cultivar para a elaboração de produtos minimamente processados.

\section{CONCLUSÕES}

1. O processamento mínimo mostrou-se viável para uvas sem sementes.

2. Os produtos minimamente processados da cv. BRS Morena e da Seleção 8 apresentaram baixo percentual de perda de massa fresca acumulada, em torno de $0,17 \%$ e $0,15 \%$, respectivamente.

3. O processamento mínimo e o armazenamento refrigerado permitiram manter a qualidade comercial da cv. BRS Morena e da Seleção 8 durante um período de 33 e 24 dias, respectivamente.

\section{REFERÊNCIAS BIBLIOGRÁFICAS}

AGRIANUAL 2003: anuário da agricultura brasileira. São Paulo: FNP - Consultoria e Comércio, 2004, p. 488-496.

AOAC. Official methods of analysis of the Association of Official Analytical Chemists. 13. ed. Washington: Ed. Patricia Cuniff, 1997. v. 2 , cap.37.

BRECHT, J.K. Physiology of lightly processed fruits and vegetables. HortScience, Alexandria, v.30, n.1, p.18-22, 1995.

CAMARGO, U.A.; NACHTIGAL, J.C.; MAIA, J.D.G; OLIVEIRA, P.R.D.; PROTAS, J.F.S. BRS Morena - Nova cultivar de uva preta de mesa sem semente. Bento Gonçalves: Embrapa Uva e Vinho, 2003. 4p. (Comunicado Técnico, 46).

CANTWELL, M.I. Fresh-cut products. Perishables Handling Newsletter, n.81, p.2-3, 1995.

CANTWELL, M.I.; SUSLOW, T.V. Postharvest Handling Systems: FreshCut Fruits and Vegetables. In: KADER, A.A. (Ed.) Postharvest technology of horticultural crops. 3.ed. Davis: University of California, 2002. p.445-463.

CARVALHO, V.D.; CHITARRA, M.I. Aspectos qualitativos da uva. Informe Agropecuário, Belo Horizonte, v.10, n.117, p.75-79, 1984.

CHITARRA, M.I.F.; CHITARRA, A.B. Pós-colheita de frutos e hortaliças: fisiologia e manuseio. Lavras: ESAL/FAEPE, 1990.320p.

CHITARRA, M.I. Colheita e pós-colheita de frutos. Informativo Agropecuário, v.17, n.179, p.8-18, 1994.

DURIGAN, J.F.; SARGENT, E.A. Uso de melão ‘Cantaloupe’ na produção 
de produtos minimamente processados. Alimentos e Nutrição, São Paulo, v.10, p.69-77, 1999.

HERNÁNDEZ, T:; BERNALTE, M.J.; SABIO, E.; VIDAL-ARAGÓ;N, M.C. Actividad peroxidasa y polifenoloxidasa de dos variedades de cereza durante la maduración. In: SIMPOSIO NACIONAL SOBRE MADURACIÓN Y POST-RECOLECCION DE FRUTOS Y HORTALIZAS, 4, 1996, Valencia. Annales... Valencia: Sociedad Española de Fisiología Vegetal, 1996. p.147-150.

KADER, A.A. (Ed.) Postharvest technology of horticultural crops. 3.ed. Davis: University of California, 2002. 535p.

KLUGE, R.A.; NACHTIGAL, J.C.; FACHINELLO, J.C.; BILHALVA, A.B. Fisiologia e manejo pós-colheita de frutas de clima temperado. 2 .ed. Pelotas:UFPEL, 2002. 216p.

MATTIUZ, B.H. Efeitos de injúrias mecânicas e do processamento mínimo na fisiologia pós-colheita de goiabas. 2002. 120f. Tese (Doutorado em Produção Vegetal) - Faculdade de Ciências Agrárias e Veterinárias, Universidade Estadual Paulista, Jaboticabal, 2002.

MATTIUZ, B.H.; DURIGAN, J.F.; ROSSI JÚNIOR, O.D. Processamento mínimo em goiabas 'Paluma' e 'Pedro Sato'. 2. Avaliação química, sensorial e microbiológica. Ciência e Tecnologia de Alimentos, Campinas, v.23, n.3, p.409-413, 2003.

MINOLTA CORP. Precise color communication: color control from feeling to instrumentation. Ramsey: Minolta Corporation Instrument Systems Division, 1994. 49p.

NACHTIGAL, J.C. Avanços tecnológicos na produção de uvas de mesa. In: CONGRESSO BRASILEIRO DE VITICULTURAEENOLOGIA, 10., 2003, Bento Gonçalves. Anais... Bento Gonçalves: Embrapa Uva e Vinho, 2003, p.167-170.

O'CONNOR-SHAW, R.E.; ROBERTS, R.; FORD, A.L.; NOTTINGHAM, S.M. Shelf life of minimally processed honeydew, kiwifruit, papaya, pineapple and cantaloupe. Journal of Food Science, Chicago, n.59, p.1202-1206, 1994.

SOUZA, R. A. M. Mercado para produtos minimamente processados. Informações Econômicas, São Paulo, v.31, n.3, p.7-18, 2001.

TEIXEIRA, G.H.A.; DURIGAN, J.F.; MATTIUZ, B.H.; ROSSI JÚNIOR, O. D. Processamento mínimo de mamão 'Formosa'. Ciência e Tecnologia de Alimentos, Campinas, v.21, n.1, p.47-50, 2001. 